criteria: NLST criteria, UKLS criteria, USPSTF criteria, LLP $\geq 5 \%$ $55-80$ yrs, and PLCO $\geq 1.51 \%$ 55-80 yrs.

Results Data was collected for 206 patients presenting between January and July 2016 (Leeds 131, Halifax 26, Bradford 12, Mid-Yorkshire 37). Median age was 72 years and the proportion of cases by age cohort was as follows: $<55$ yrs $9.2 \%, 55-60$ yrs $9.7 \%$, 61-65 yrs $12.1 \%$, 66-70 yrs $13.6 \%$, 71-75 yrs $18.4 \%$, $76-80$ yrs $17.0 \%,>80$ yrs $19.9 \%$. Smoking status was: current smoker 89 (43.2\%), ex-smoker 106 (51.5\%) and never smoker $11(5.3 \%)$. The number of patients eligible by the various criteria are shown in Table 1.

Conclusion The proportion of lung cancer patients who would have been eligible for screening differs considerably between the various criteria. Only approximately one third of patients would have been eligible according to the criteria used in NLST and UKLS. Increasing the upper age limit for screening to $80 \mathrm{yrs}$ substantially increases the proportion of cases that would be eligible. A threshold of $1.51 \%$ by the PLCO $_{\mathrm{M} 2012}$ score included the largest number of lung cancer patients of the criteria assessed.

\section{S130 THE PREVALENCE OF UNDIAGNOSED COPD ON SPIROMETRY AND EMPHYSEMA ON LOW-DOSE CT SCANS IN A LUNG CANCER SCREENING DEMONSTRATION PILOT: A TEACHABLE MOMENT?}

${ }^{1} \mathrm{C}$ Horst, ${ }^{1} \mathrm{M}$ Ruparel, ${ }^{2} \mathrm{~S}$ Quaife, ${ }^{3} \mathrm{~A}$ Ahmed, ${ }^{3} \mathrm{M}$ Taylor, ${ }^{4} \mathrm{~A}$ Bhowmik, ${ }^{5} \mathrm{~S}$ Burke, ${ }^{3} \mathrm{P}$ Shaw, ${ }^{2} \mathrm{~A}$ McEwen, ${ }^{2} \mathrm{~J}$ Waller, ${ }^{6} \mathrm{DR}$ Baldwin, ${ }^{7} \mathrm{~N}$ Navani, ${ }^{1} \mathrm{R}$ Thakrar, ${ }^{1} \mathrm{SM}$ Janes. ' Lungs For Living, UCL Respiratory, University College London, London, UK; ${ }^{2}$ Health Behaviour Research Centre, University College London, London, UK; ${ }^{3}$ Radiology Department, University College London Hospital, London, UK; ${ }^{4}$ Thoracic Medicine, Homerton University Hospital, London, UK; ${ }^{5}$ Radiology Department, Homerton University Hospital, London, UK; ${ }^{6}$ Respiratory Medicine Unit, David Evans Research Centre, Nottingham University Hospitals, Nottingham, UK; ${ }^{7}$ Thoracic Medicine, University College London Hospital, London, UK

\subsection{6/thoraxjnl-2016-209333.136}

Introduction and objectives Chronic obstructive pulmonary disease (COPD) and emphysema are considerably under-diagnosed conditions. Low dose CT (LDCT) for lung cancer screening, if implemented, may provide an opportunity for earlier diagnosis of smoking-related conditions, in addition to lung cancer. Data gathered in a lung cancer screening demonstration pilot was analysed to look at COPD-related radiological changes and their relationship with patients' pre-existing diagnoses, spirometry results and smoking status. The aims were to better understand these interlinked conditions and identify the potential for earlier diagnosis and management of smoking cessation interventions for these conditions.

Methods Data were collected as part of the Lung Screen Uptake Trial. Smokers and recent former smokers (quit $<5$ years) aged 60-75 were invited to a 'lung health check' via their general practitioner (GP). Data on pre-existing diagnoses, smoking status and pre-bronchodilation spirometry, categorised according to the National Institute for Clinical Excellence (NICE) criteria, were collected. Patients who met the eligibility criteria for screening went on to have LDCT. Results were analysed for frequencies, and confidence intervals calculated for the most significant results.

Results 275 patients responded to an invitation to attend a 'lung health check' in the first six months of recruitment. 149 (54.2\%) had values consistent with COPD on spirometry. 106 [71.1\%, (95\% CI: $\pm 7.3 \%)$ ] of these individuals were not aware of a diagnosis of COPD, and 81 (76.4\%) were current smokers (Figure 1). Of the 103 individuals who had emphysema and no suspicious lesion on LDCT, 74 [71.8\%, (95\% CI: $\pm 8.7 \%)$ ] were not aware of a diagnosis of COPD or emphysema. 55 (74.3\%) of these were current smokers, and $33(44.6 \%)$ had preserved spirometry (Table 1).

Conclusion Our data demonstrate the considerable burden of undiagnosed COPD in at-risk groups $38.5 \%$ of all screened individuals), and show the prevalence of emphysematous change in those patients without a pre-existing, self-reported diagnosis of COPD or with preserved spirometry. Early diagnosis and CT evidence of smoking damage may provide the opportunity to coimplement supportive smoking cessation interventions, earlier

Abstract S130 Table 1 Smoking status and severity of COPD on spirometry and severity of emphysema on LDCT. Shaded columns represent the patients within that category who reported a pre-existing diagnosis of COPD or emphysema.

\begin{tabular}{|c|c|c|c|c|c|c|c|c|c|c|c|}
\hline & & \multicolumn{10}{|c|}{ Severity of COPD based on NICE criteria for COPD (2004) (3)* } \\
\hline & & \multicolumn{2}{|c|}{ Normal } & \multicolumn{2}{|l|}{ Mild } & \multicolumn{2}{|c|}{ Moderate } & \multicolumn{2}{|l|}{ Severe } & \multicolumn{2}{|l|}{ Totals } \\
\hline & & $\#$ & $\%$ with PMHx COPD & $\#$ & $\%$ with PMHx COPD & \# & $\%$ with PMHx COPD & \# & $\%$ with PMHx COPD & $\#$ & $\%$ with PMHx COPD \\
\hline & & Cases & & Cases & & Case & & Cases & & Cases & \\
\hline \multirow[t]{4}{*}{ Smoking Status } & No smoking data & 0 & & 0 & & 1 & $100 \%$ & 0 & & 1 & $100 \%$ \\
\hline & Current smoker & 76 & $10.5 \%$ & 39 & $12.8 \%$ & 46 & $30.4 \%$ & 18 & $50.0 \%$ & 179 & $20.1 \%$ \\
\hline & Former smoker & 43 & $11.6 \%$ & 13 & $23.1 \%$ & 19 & $36.8 \%$ & 5 & $40.0 \%$ & 80 & $21.3 \%$ \\
\hline & Occasional smoker & 7 & $0 \%$ & 4 & $0 \%$ & 2 & $50.0 \%$ & 2 & $50.0 \%$ & 15 & $13.3 \%$ \\
\hline \multirow[t]{5}{*}{ Total } & & 126 & $10.3 \%$ & 56 & $14.3 \%$ & 68 & $33.8 \%$ & 25 & $48 \%$ & 275 & $20.4 \%$ \\
\hline & & \multicolumn{10}{|c|}{ Severity of Emphysema on CT } \\
\hline & & \multicolumn{2}{|c|}{ Not present } & \multicolumn{2}{|l|}{ Mild } & \multicolumn{2}{|c|}{ Moderate } & \multicolumn{2}{|l|}{ Severe } & \multicolumn{2}{|l|}{ Totals } \\
\hline & & $\#$ & $\%$ with PMHx COPD & \# & $\%$ with $\mathrm{PMHx}$ COPD & \# & $\%$ with $\mathrm{PMHx}$ COPD & $\#$ & $\%$ with PMHx COPD & \# & $\%$ with $\mathrm{PMH}$ (COPD \\
\hline & & Cases & & Cases & & Case & & Cases & & Cases & \\
\hline \multirow[t]{3}{*}{ Smoking Status } & Current smoker & 37 & $5.4 \%$ & 40 & $17.5 \%$ & 25 & $28.0 \%$ & 8 & $75.0 \%$ & 110 & $20.0 \%$ \\
\hline & Former smoker & 28 & $14.2 \%$ & 16 & $31.3 \%$ & 8 & $12.5 \%$ & 3 & $66.7 \%$ & 55 & $21.8 \%$ \\
\hline & Occasional smoker & 5 & $0 \%$ & 1 & $0 \%$ & 0 & $0 \%$ & 2 & $50.0 \%$ & 8 & $12.5 \%$ \\
\hline Total & & 70 & $8.6 \%$ & 57 & $21.1 \%$ & 33 & $24.2 \%$ & 13 & $69.2 \%$ & 173 & $20.2 \%$ \\
\hline
\end{tabular}

*Spirometry values are pre-bronchodilator results, categorised by severity according to 2004 NICE criteria: National Collaborating Centre for Acute and Chronic Conditions. Chronic obstructive pulmonary disease in over 16s: diagnosis and management. 2010;(June). 
medical intervention and prevention of further progression of disease through improved management of these conditions.

\section{S131 WHAT PROPORTION OF THE UK POPULATION WOULD BE ELIGIBLE FOR CT SCREENING FOR LUNG CANCER ACCORDING TO VARIOUS PROPOSED INCLUSION CRITERIA?}

K Gracie, M Kennedy, J Robson, M Callister. Leeds Teaching Hospitals NHS Trust, Leeds, UK

\subsection{6/thoraxjnl-2016-209333.137}

Introduction Low dose CT screening reduced lung cancer mortality by $20 \%$ in the National Lung Screening Trial (NLST) using eligibility criteria of age 55-74 yrs, $\geq 30$ pack year smoking history, and quit time $<15$ years. The US Preventative Services Task Force (USPSTF) has proposed using the NLST criteria extending the upper age limit to 80 years. Alternative proposed eligibility criteria use thresholds from composite risk prediction scores such as a $1.51 \%$ lung cancer risk over 6 years using the PLCO $_{M 2012}$ model (derived from the Prostate Lung Colorectal and Ovarian Study) and a 5\% lung cancer risk over 5 years using the Liverpool Lung Project (LLP) model (used in the UK Lung Screening trial). We sought to compare the proportions of patients in the UK who would be eligible for screening according to these criteria.

Methods We commissioned an anonymous telephone survey in Yorkshire (Hull, Leeds and Wakefield) to collect parameters to calculate lung cancer risk ( PLCO $_{\mathrm{M} 2012}$ and LLPv.2) and likelihood of participation in a future programme. Index of multiple deprivation (IMD) was recorded based on postcode and used to ensure a representative cohort. No patient identifiable information was entered into the research database.
Results 2,424 persons 55-80 years agreed to participate in the telephone survey, of which 1,335 were ever-smokers. The proportion of patients $(95 \% \mathrm{CI})$ eligible according to various criteria were as follows: NLST 11.9\% (10.6\%-13.2\%), USPSTF $13.3 \%$ (12.0\%-14.7\%), PLCO $_{\mathrm{M} 2012} \geq 1.51 \% \quad 20.7 \% \quad(19.1 \%-22.3 \%)$ and LLP $\geq 5 \% 15.8 \%(14.4 \%-17.3 \%)$. The proportions eligible by USPSTF, PLCO and LLP criteria by IMD and age cohort are shown in Figure 1. When asked how likely they would be to attend an NHS lung cancer screening programme, 62.6\% indicated 'very likely'. This proportion was similar between those eligible for screening by any criteria and those not $(62.5 \%$ and $62.7 \%$ respectively) and current and ex-smokers $(61.4 \%$ and $63.0 \%$ respectively).

Discussion The proportions of the population eligible for screening differ considerably between various eligibility criteria, and according to deprivation and age. The criteria selected to determine screen-eligibility in a future national screening programme will have a significant impact on the cost and cost-effectiveness of such a programme.

\section{S132 A RANDOMISED CONTROLLED STUDY OF LUNG CANCER SCREENING IN SCOTLAND USING THE DETECTION OF AUTOANTIBODIES TO TUMOUR ANTIGENS (EARLYCDT-LUNG TEST)}

${ }^{1} \mathrm{~A}$ Dorward, ${ }^{1} \mathrm{~F}$ Frances Mair, ${ }^{2} \mathrm{~F}$ Sullivan, ${ }^{3} \mathrm{~K}$ Vedhara, ${ }^{3} \mathrm{D}$ Kendrick, ${ }^{4} \mathrm{~S}$ Treweek, ${ }^{5} \mathrm{C}$ McCowan, ${ }^{5} \mathrm{~A}$ McConnachie, ${ }^{1} \mathrm{M}$ Sproule, ${ }^{5} \mathrm{~A}$ Briggs, ${ }^{4} \mathrm{~L}$ Ritchie, ${ }^{1} \mathrm{R}$ Milroy, ${ }^{6} \mathrm{~T}$ Taylor, ${ }^{7} \mathrm{R}$ Littleford, ${ }^{8} \mathrm{D}$ Brewster, ${ }^{6} \mathrm{~S}$ Schembri. ${ }^{7} \mathrm{NHS}$ Greater Glasgow and Clyde, Glasgow, UK; ${ }^{2}$ University of Toronto, Toronto, Canada; ${ }^{3}$ University of Nottingham, Nottingham, UK; ${ }^{4}$ University of Aberdeen, Aberdeen, UK; ${ }^{5}$ University of Glasgow, Glasgow, UK; ${ }^{6} \mathrm{NHS}$ Tayside, Dundee, UK; ${ }^{7} T C T U$, University of Dundee, Dundee, UK; ${ }^{8}$ Scottish Cancer Registry, Edinburgh, UK

10.1136/thoraxjnl-2016-209333.138

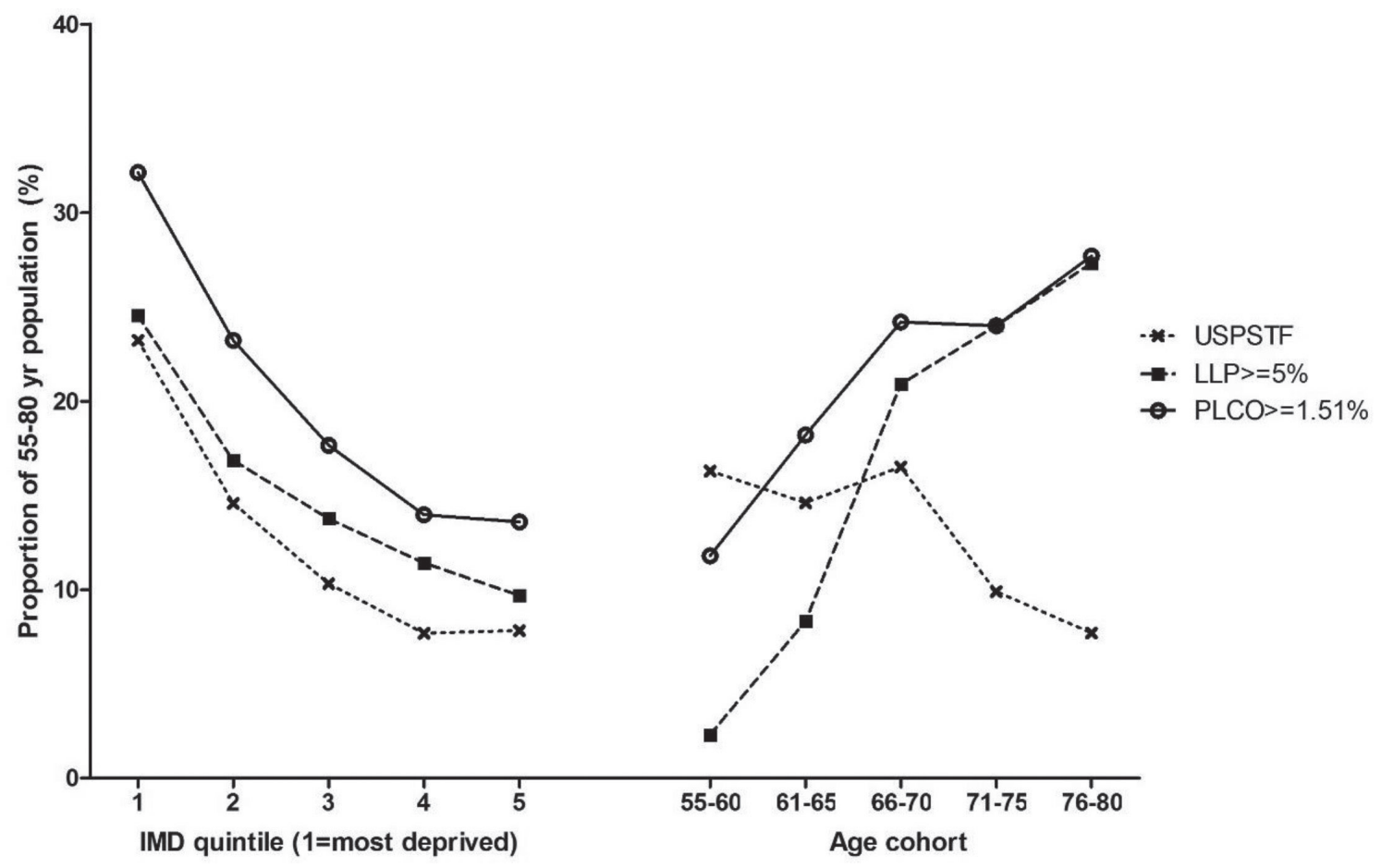

Abstract S131 Figure 1 The proportion of 55-80 year old population eligible for screening by various criteria by IMD quintile and age 